Archives de sciences sociales des religions

\title{
Chrétiens au Proche-Orient
}

\section{Présentation}

Pierre Antoine Fabre

\section{(2) OpenEdition}

Journals

Édition électronique

URL : http://journals.openedition.org/assr/27124

DOI : $10.4000 /$ assr. 27124

ISSN : $1777-5825$

Éditeur

Éditions de l'EHESS

Édition imprimée

Date de publication : 1 septembre 2015

Pagination : 211-212

ISBN : 9-782713224706

ISSN : 0335-5985

\section{Référence électronique}

Pierre Antoine Fabre, «Présentation », Archives de sciences sociales des religions [En ligne], 171 | 2015, mis en ligne le 01 septembre 2018, consulté le 24 septembre 2020. URL : http://

journals.openedition.org/assr/27124; DOI : https://doi.org/10.4000/assr.27124 


\section{Heidegger 1920-1927}





\section{Présentation}

Le petit dossier réuni ici ${ }^{1}$ trouve sa première origine dans une séminaire organisé à l'École des hautes études en sciences sociales le 20 février 2013, à l'occasion de la publication récente du Cours donné par Martin Heidegger sur une Phénoménologie de la vie religieuse, œuvre jusqu'alors inconnue du public français. Cours de jeunesse, plusieurs années avant 1927 et l'amorce, avec et après Sein und Zeit, d'une transformation de la phénoménologie dans une histoire historiale de l'être.

Nous sommes au seuil des années 1920, dans une situation allemande que rappelle bien la remarque de Heidegger ${ }^{2}$ : «S'imaginer que l'on puisse liquider la théologie d'un tour de main est un préjugé des philosophes de la religion ». Il ne faut pas perdre de vue ici le sens de la "philosophie de la religion ", en Allemagne, comme voie émancipatrice par rapport à l'emprise de la religion ellemême sur la philosophie en général, et comme ouverture de la philosophie sur d'autres sciences (c'est à Ernst Troeltsch, bien connu des lecteurs des Archives de sciences sociales des religions, que s'adresse Heidegger principalement ici). Nous sommes dans une situation où l'emprise académique de la théologie n'a pas du tout été éradiquée, et sa position de " reine des sciences " pas radicalement contestée. Il n'y a pas eu, là non plus, de révolution allemande. Inversement, nous savons comment la promotion française de la philosophie au comble de la science a exclu la théologie comme discipline savante, et qu'elle est aujourd'hui seulement réexaminée, non seulement comme pratique professionnelle, en quelque sorte, mais aussi dans certaines des empreintes qu'elle a pu souterrainement continuer de marquer dans l'histoire de la pensée, en particulier au tournant du XXe siècle à l'époque de la "naissance des sciences sociales ».

Il est pour nous d'autant plus précieux de revenir à ce moment des années 1919-1920. La question étant : que reste-t-il pour Heidegger dans la « théologie »

1. Deux articles complétés par un choix de lettres échangées entre Heidegger et Rudolf Bultmann, correspondance essentielle pour la compréhension de cette période.

2. M. Heidegger, Phénoménologie de la vie religieuse, traduit de l'allemand par Jean Greish, Paris, Gallimard, 2012, p. 32. 
là où il semble la placer à l'écart de cette première distance vis-à-vis de la religion qu'a été la "philosophie de la religion ».

Si la théologie est, en dernière instance, une connaissance actuelle de Dieu, il faut être attentif au fait que la «destruction » ou déconstruction heideggérienne est une destruction de l'histoire de l'être, de l'histoire de l'oubli de l'être, et non pas de son actualité, ou de son événement - termes centraux du cours de 1920 qui appellent une autre historicité, non pas l'historicité objective qui serait celle de l'oubli de l'être, mais une histoire du présent, de la "situation ». La question de la théologie n'est donc pas résolue par Heidegger dans celle de l'être, c'est au contraire la question de l'être qui l'attache à penser l'actualité de ou dans la théologie. Tout ceci plus vrai encore en 1920, quand l'entreprise de « destruction » de la métaphysique n'est pas encore lancée, mais quand pourtant, et par le "temps » de la théologie, une autre historicité se cherche déjà. C’est cette situation - je reprends ici à dessein le mot - qui est remarquable.

Dans une première approximation de ce Cours, pour le dire vite en conclusion de cette rapide présentation, ce qui frappe c'est le basculement ${ }^{3}$ de la première partie, "Introduction méthodologique ", dans un commentaire de Paul. Basculement d'un discours dans un commentaire de l'Écriture, et qui plus est dans un récit, ou plus précisément dans un discours réenchâssé dans un récit, dans une «Proclamation » qui n'est pas le présent perpétuel d'un discours, mais l'ici et maintenant situé d'un récit. En première approximation, la résistance de la théologie apparaîtrait ici comme la résistance d'un discours précaire, toujours ouvert sur sa seule vérité ultime, l'Écriture dont elle procède dans son noyau narratif même.

Il me reste à remercier Claudia Serban et Laurent Villevieille, spécialistes de la phénoménologie entre Husserl et Heidegger, d'avoir accepté de contribuer aux travaux des Archives, en prolongement et en écho du grand ensemble coordonné par Vincent Delecroix et Philippe Portier dans la dernière livraison de la Revue, "Philosophie et Religion ». Cette séquence réaffirme la place de la philosophie dans le paysage des sciences sociales, une place marquée, depuis les travaux de Jacques Derrida en particulier, par une critique des savoirs historiques et par une relation mouvementée et active avec la pensée de Heidegger.

Pierre Antoine FABRE

3. Claudia Serban et Laurent Villevieille insistent l'un et l'autre sur la précipitation tactique de ce basculement après que le public du Cours de 1920 ait protesté contre une trop longue introduction, trop éloignée - justement - de la "philosophie de la religion ». Mais la rupture reste significative, me semble-t-il, entre les deux registres. 